\title{
Dietary patterns by reduced rank regression are associated with obesity and hypertension in Australian adults
}

\author{
Katherine M. Livingstone* and Sarah A. McNaughton \\ School of Exercise and Nutrition Sciences, Institute for Physical Activity and Nutrition, Deakin University, Geelong, VIC 3125, \\ Australia \\ (Submitted 27 September 2016 - Final revision received 28 November 2016 - Accepted 8 December 2016 - First published online 25 January 2017)
}

\section{Abstract}

Evidence linking dietary patterns (DP) and obesity and hypertension prevalence is inconsistent. We aimed to identify DP derived from energy density, fibre and sugar intakes, as well as $\mathrm{Na}$, K, fibre, SFA and PUFA, and investigate associations with obesity and hypertension. Adults ( $n$ 4908) were included from the cross-sectional Australian Health Survey 2011-2013. Two 24-h dietary recalls estimated food and nutrient intakes. Reduced rank regression derived DP with dietary energy density (DED), fibre density and total sugar intake as response variables for obesity and Na:K, SFA:PUFA and fibre density as variables for hypertension. Poisson regression investigated relationships between DP and prevalence ratios (PR) of overweight/obesity (BMI $\geq 25 \mathrm{~kg} / \mathrm{m}^{2}$ ) and hypertension (blood pressure $\geq 140 / 90 \mathrm{mmHg}$ ). Obesity-DP1 was positively correlated with fibre density and sugars and inversely with DED. Obesity-DP2 was positively correlated with sugars and inversely with fibre density. Individuals in the highest tertile of Obesity-DP1 and Obesity-DP2, compared with the lowest, had lower (PR 0.88; $95 \%$ CI 0.81, 0.95) and higher (PR 1.09; 95\% CI 1.01, 1.18) prevalence of obesity, respectively. Na:K and SFA:PUFA were positively correlated with Hypertension-DP1 and inversely correlated with Hypertension-DP2, respectively. There was a trend towards higher hypertension prevalence in the highest tertile of Hypertension-DP1 compared with the lowest (PR 1.18; 95\% CI 0.99, 1.41). Hypertension-DP2 was not associated with hypertension. Obesity prevalence was inversely associated with low-DED, high-fibre and high-sugar (natural sugars) diets and positively associated with low-fibre and high-sugar (added sugars) diets. Hypertension prevalence was higher on low-fibre and high-Na and SFA diets.

Key words: Dietary patterns: Reduced rank regression: Hypertension: Obesity: Adults

Obesity and hypertension are among the primary risk factors for chronic diseases, including CVD, with 9.4 million deaths worldwide from CVD per year attributable to hypertension alone ${ }^{(1)}$. The World Health Organization has identified that there is convincing evidence that obesity and poor diet are associated with increased risk of $\mathrm{CVD}^{(2)}$. Moreover, the WHO has proposed that a high-Na and high-SFA diet and a low-K diet are associated with increased risk of CVD, whereas a diet high in energy-dense foods and low in fibre is associated with increased risk of obesity.

Given that nutrients are not eaten in isolation and that the WHO recommends the study of whole foods rather than nutrients ${ }^{(3)}$, identification of dietary patterns (DP) may be more informative than looking at nutrients in isolation. Two main approaches are used to derive DP: (i) hypothesis-driven diet quality scores and (ii) exploratory, data-driven analyses such as cluster or factor analysis. The latter offers the advantage of considering the correlation structure of food intakes, yet often fails to predict disease outcomes $^{(4)}$. Reduced rank regression (RRR) is a combined approach that utilises both exploratory, data-driven analyses and a priori knowledge of a disease ${ }^{(5)}$, which has been shown to derive DP that predict disease outcomes ${ }^{(6,7)}$. Moreover, unlike purely data-driven approaches such as principal component analysis (PCA), RRR provides a valuable link between nutrient and food-based approaches ${ }^{(8)}$. The strength of using RRR over investigating the relationship between nutrient or food intakes in isolation is its ability to account for the correlation of nutrient intakes, which are specific to the disease of interest and which will inform the data-driven generation of DP.

Because of the heterogeneity of DP methodologies, relationships between DP and obesity ${ }^{(4,9)}$ and hypertension are inconsistent ${ }^{(4,10,11)}$. In particular, limited studies in nutritional epidemiology have utilised $\mathrm{RRR}^{(4)}$. Recent studies have identified that RRR DP based on energy density and fat and fibre intakes are associated with obesity ${ }^{(12,13)}$. In addition, a longitudinal study of 24958 European adults identified that a RRR DP characterised by low-fat and high-fibre intake was associated with obesity ${ }^{(14)}$. To date, only one study has investigated RRR in relation to hypertension risk specifically ${ }^{(15)}$.

Abbreviations: DP, dietary pattern; DED, dietary energy density; PR, prevalence ratio; RRR, reduced rank regression; WC, waist circumference.

* Corresponding author: Dr K. M. Livingstone, email k.livingstone@deakin.edu.au 
This study by da Silva et al. ${ }^{(15)}$ included a diet high in $\mathrm{K}$ and low in $\mathrm{Na}$ and SFA that was inversely associated with hypertension. However, these findings were only significant in women between 40 and 60 years of age ${ }^{(15)}$. Given the unique and novel strengths of the RRR methodology and its limited application to nutritional epidemiology to date, further studies are needed to improve our understanding of the relationship between RRR-derived DP and risk of obesity and hypertension.

The present study investigated DP derived using RRR and 24-h recall data from the Australian National Nutrition and Physical Activity Survey (NNPAS), a nationally representative cross-sectional study of Australian households ${ }^{(16)}$. The aim of this analysis was to investigate the relationships between these $\mathrm{DP}$ and prevalence ratio (PR) of obesity and hypertension in Australian adults.

\section{Methods \\ Subjects and study design}

Adults ( $\geq 19$ years, $n$ 4971) from a subset of the latest $(2011 / 2013$ ) Australian Health Survey (AHS) ${ }^{(16)}$, NNPAS, were included in the present analyses. As described elsewhere ${ }^{(16)}$, the AHS is a population-based survey that sampled urban and rural households across all Australian states and territories. The following individuals were excluded from the survey: living in very remote areas and discrete Aboriginal and Torres Strait Islander communities; living in non-private dwellings such as hotels and hospitals; certain diplomatic personnel of overseas governments, customarily excluded from the Census and estimated resident population; persons whose usual place of residence was outside Australia; members of non-Australian Defence Forces (and their dependents) stationed in Australia; and visitors to private dwellings. A total of 14363 private dwellings were selected in the NNPAS ( $n 12366$ dwellings after sample loss in the field stage), of which 9519 (77.0\%; $n 12153$ individuals) were fully or adequately responding households to the first interview. Dietary intakes were estimated using two 24-h dietary recalls. Of the 9519 dwellings in the first interview, 7735 (63.6\%) dwellings completed the second dietary recall. Anthropometric and blood pressure measures were collected on a voluntary basis by trained interviewers during home visits. For the present analysis, individuals were excluded if they (i) were pregnant and/or breast-feeding, (ii) only completed $1 \mathrm{~d}$ of dietary recall or (iii) had missing data for anthropometric measurements and blood pressure and covariates (Fig. 1). Ethics approval was granted by the Australian Institute for Health and Welfare. Further information on the design and methodologies of these surveys is presented elsewhere ${ }^{(16)}$.

\section{Study measures}

Obesity-related outcomes. Weight $(\mathrm{kg})$, height $(\mathrm{cm})$ and waist circumference (WC; $\mathrm{cm}$ ) were measured using digital scales, a stadiometer and a metal tape, respectively. Before measurements were taken, subjects were asked to remove their shoes and any heavy clothing, although this was not compulsory. BMI was derived using Quetelet's metric $\left(\mathrm{kg} / \mathrm{m}^{2}\right)$. Standard cutoffs for BMI and WC were applied: underweight/normal weight,
BMI $<25 \mathrm{~kg} / \mathrm{m}^{2} ;$ overweight, $\mathrm{BMI} \geq 25 \mathrm{~kg} / \mathrm{m}^{2}$ and $<30 \mathrm{~kg} / \mathrm{m}^{2}$; obese, $\quad \mathrm{BMI} \geq 30 \mathrm{~kg} / \mathrm{m}^{2}$; and $\mathrm{WC}$, central adiposity $>102 \mathrm{~cm}$ (men) and $>88 \mathrm{~cm}$ (women) ${ }^{(17)}$.

Blood pressure and hypertension. Systolic and diastolic blood pressure measurements were obtained using an automated blood pressure monitor on the left arm, unless there was a prohibitive reason such as an injury. Two measurements were taken, and if there was a significant difference $(>10 \mathrm{mmHg})$ between the readings, for either diastolic or systolic readings, the CAI instrument would prompt for a third reading. Individuals were categorised into non-hypertensive (blood pressure $<140 / 90 \mathrm{mmHg}$ ) and hypertensive $(\geq 140 / 90 \mathrm{mmHg}$ ) for the purpose of this study. Data on hypertensive medication were not recorded ${ }^{(18)}$.

Socio-demographic characteristics. Socio-demographic characteristics were collected via interviewer-administered questionnaires. Smoking habits were categorised as current, ex-smoker and never smoked. Education status was operationalised as low (completed some high school or less), medium (completed high school or completed some high school and/or certificate/ diploma) and high (having a tertiary qualification) on the basis of the Australian Standard Classification of Education 2001. Urban or rural location was categorised as major city, inner rural or other on the basis of the Australian Statistical Geography Standard classification system, which is estimated from factors such as population density and distance to the nearest population centre ${ }^{(19)}$. Physical activity was assessed by questionnaire items on physical activity/exercise undertaken in the last week: walking for transport, walking for fitness, time spent in moderate and vigorous activity and session numbers. Items were combined to estimate whether participants met or did not meet physical activity guidelines (i.e. $150 \mathrm{~min}$ physical activity/week and $150 \mathrm{~min}$ over five or more sessions per week). Sedentary behaviour was defined as time spent $(\mathrm{min} / \mathrm{d})$ sitting or lying down for various activities, including time spent sitting at work and time spent sitting while using computers, watching television and for other leisure activities. Incidence of dieting or atypical dietary intakes on the day of reporting was recorded. Female life stage was categorised as never having menstruated, experiencing menopause or postmenopause.

Dietary intake. Quantitative information on foods and beverages consumed on the day before the interview was collected using a multiple-pass, 24-h dietary recall based on the United States Department of Agriculture's Automated Multiple-Pass Method 24-h dietary recall ${ }^{(20)}$. The interview was divided into five phases: quick list description of food and beverages consumed from midnight to midnight the previous day, prompt the respondent to remember any omitted foods, provide information on time and eating occasion, further details (including preparation method and brand names) and a final probe to recall any omitted foods or beverages ${ }^{(16)}$. A second 24-h recall was collected via telephone interview at least $8 \mathrm{~d}$ after the first interview. Nutrient intakes were derived from the 24-h recalls using AUSNUT 2011-13 food composition database developed by Food Standards Australia New Zealand and was based on 
5740 foods $^{(21)}$. Energy misreporting was accounted for by adjusting models for the ratio of energy intake:predicted total energy expenditure (using sex- and age-specific equations for a range of weight status, assuming a physical activity level (PAL) of 'low active' $\mathrm{PAL} \geq 1 \cdot 4<1 \cdot 6)^{(22)}$. Participants were identified as plausible reporters, under-reporters or over-reporters of energy intake using published equations to calculate the $\pm 1 \mathrm{sD}$ cut-off for ratio of energy intake:predicted total energy expenditure $^{(22,23)}$. The present analysis included participants who completed both 24-h dietary recalls. Dietary intakes were an average across both recalls to limit misreporting bias between day 1 (plausible energy reporters: $80 \cdot 1 \%$ ) and day $2(67 \cdot 3 \%)^{(24)}$.

Dietary pattern determination. DP were determined using RRR, a statistical technique designed to derive DP that maximise the variation explained by response variables selected on the basis of an a priori hypothesis that they are related to the outcome of interest ${ }^{(5)}$. For deriving RRR DP for use in the analysis of obesity outcomes (referred to as Obesity-DP), dietary energy density (DED), fibre density and fat intake were selected as response variables. These nutrients were selected on the basis of evidence from the WHO report on prevention of chronic disease, and relevant literature that suggests that DED, fibre density and sugar intakes are strongly associated with obesity risk ${ }^{(2,25)}$. Similarly, strong evidence from the WHO and relevant literature suggest that increased intake of Na:K, SFA:PUFA and fibre density are strongly associated with CVD risk ${ }^{(2,15,26)}$. As a result, these variables were selected as response variables in the estimation of RRR DP for use in hypertension analyses (referred to as Hypertension-DP). Recent studies have substantiated the use of these response variables for deriving DP associated with risk of obesity $^{(12)}$ and hypertension ${ }^{(15)}$. DED was calculated by dividing total food energy $(\mathrm{kJ})$ by total food weight $(\mathrm{g})$ and excluded all beverages, other than dairy beverages, because of their disproportionate influence on total DED value. This method for deriving DED has been described elsewhere ${ }^{(27)}$ and has been recommended because of its disaggregation of dairy beverages from sugar-containing drinks and alcohol and its comparability with the World Cancer Research Fund DED definition ${ }^{(28)}$. Fibre density was expressed as absolute intake of fibre $(\mathrm{g} / \mathrm{d}$ ) divided by total daily energy intake (MJ).

A total of forty-eight food groups $(\mathrm{g} / \mathrm{d}$ ) were used as predictors in the RRR analyses. These groups were based on the AUSNUT 2011-13 food group classification system ${ }^{(29)}$ and were revised according to nutrient profiles (e.g. fat content) and the published literature ${ }^{(14,15)}$. Foods were grouped according to the following categories: non-alcoholic beverages (one group), cereals (seven groups), fats and oils (two groups), fruits (eight groups), vegetables (eight groups), meat and alternatives (seven groups), dairy products (five groups), soups and sauces (two groups), snacks and confectionery (four groups) and alcoholic beverages (three groups). The number of extracted patterns is dependent on the number of response variables; thus, intakes $(\mathrm{g} / \mathrm{d})$ of all forty-eight food groups and the three response variables were used to derive three DP. To test the robustness of the DP, DP were derived in a $50 \%$ random sample split. To derive a DP that captured the food groups that contributed most to the RRR pattern, a simplified score was derived and used in a sensitivity analysis based on previously utilised methodologies ${ }^{(14,30)}$. This score was generated by summing the standardised food intakes, only including food groups with factor loadings greater than $|>0 \cdot 17|$, based on previously used cut-offs ${ }^{(25,30)}$.

Statistical analyses. Complete case analysis was used to address missing data (details of missing data are presented in Fig. 1). DP identified from RRR were categorised into sex-specific tertiles, with the lowest tertile (representing individuals with the lowest DP score) used as the reference group. Variables were tested for skewness and kurtosis and were log transformed if not normally distributed. BW, BMI and WC were not normally distributed, and therefore were log transformed before analysis. Pairwise correlation coefficients were used to investigate correlations between DP and response variables for obesity and hypertensionrelated outcomes. Multiple variable-adjusted logistic and linear regressions were used to test for significant associations between dietary intakes and demographic characteristics (dependent variables) and tertiles of DP score (independent variable) for categorical and continuous variables, respectively. Poisson regression was used to test for significant associations across tertiles of DP score (independent variable) and PR of being overweight or obese, having central adiposity or being hypertensive (dependent variables). Analyses were adjusted for age (continuous), sex, smoking (categorical), physical activity (binary), level of education (categorical), urban or rural location (categorical), energy misreporting (continuous), dieting or atypical dietary intake on the day of reporting (categorical), and female life stage (categorical; women only). Hypertension-related outcomes were further adjusted for BMI. We examined the impact of potential effect modifiers on the association between DP and obesity and hypertension by including an interaction term in the linear regression models for the following variables: sex, age $(<50$ and $\geq 50$ years) and BMI $\left(<30\right.$ and $\left.\geq 30 \mathrm{~kg} / \mathrm{m}^{2}\right)$. There was evidence of effect modification by age on BMI $\left(P_{\text {interaction }}<0.05\right)$. Although no other interactions were observed, the previous literature suggests that obesity and hypertension outcomes may be modified by sex and $\mathrm{BMI}^{(14,15)}$, and therefore the results are presented for an overall effect and by age, sex and BMI strata. A sensitivity analysis was run to test for associations between the simplified DP and prevalence of obesity-related outcomes and hypertension. Sensitivity analyses were run to further evaluate the effect of energy misreporting by (i) analysing the full cohort without adjusting for energy misreporting and (ii) excluding energy misreporters from the analyses. To investigate intra-person variation in dietary intakes between days of recall, RRR DP were derived for day 1 and day 2 independently, and usual intakes were estimated using the web-based statistical modelling technique Multiple Source Method (version 1.0.1, 2011; German Institute of Human Nutrition Potsdam-Rehbrücke) ${ }^{(31)}$. This software has been used previously to estimate usual nutrient and food intakes of individuals and population groups on the basis of data from two or more shortterm dietary measurements, including two $24-\mathrm{h}$ recalls ${ }^{(32,33)}$. The relationships between DP estimated using dietary intakes from day 1 , day 2 , the average of both days and usual intakes and obesity and hypertension outcomes were compared. 
SAS (version 9; SAS Institute) was used to derive RRR DP Logistic, Poisson and linear regressions were conducted using Stata (version 14; StataCorp LP) using survey weights that account for the survey design. Survey weights were specifically designed to account for bias associated with those who volunteered to complete the second day of dietary recalls. $P<0.05$ was considered statistically significant.

\section{Results}

\section{Correlations between dietary patterns and dietary intakes}

As summarised in Fig. 1, a total of 4908 individuals were included in the present study (men: $n$ 2346; women: $n$ 2562). The explained variations in food intakes and response variables and the correlations between response variables and DP are summarised in Table 1 . Food groups with the top five positive and negative factor loadings for each DP are presented in Tables 2 and 3 for obesity and hypertension, respectively. As the third DP explained $<10 \%$ of the variation in response variables for both obesity and hypertension, it was not further investigated. The following results are for two obesity-related DP (Obesity-DP1 and Obesity-DP2) and two hypertensionrelated DP (Hypertension-DP1 and Hypertension-DP1).

Obesity-related dietary patterns. Obesity-DP1 was positively correlated with fibre density $(r$ 0.69) and percentage energy intake from sugars $(r 0.24)$ and negatively correlated with DED $(r-0 \cdot 75)$. In contrast, Obesity-DP2 was positively correlated with percentage energy intake from sugars $(r$ 0.69) and negatively correlated with fibre density $(r-0 \cdot 24$; Table 1$)$.

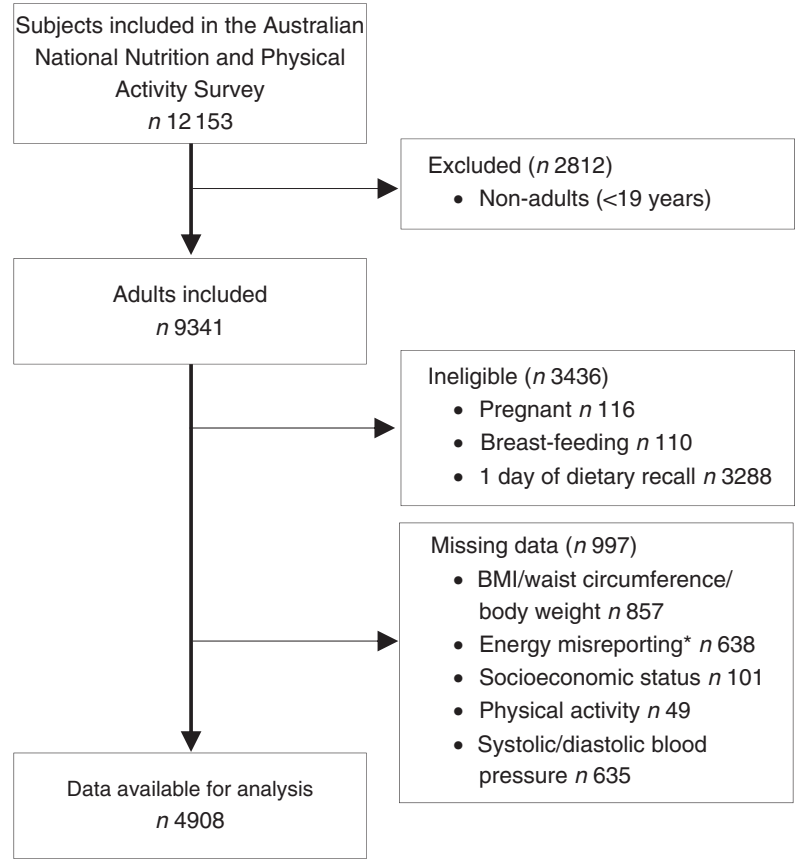

Fig. 1. Flow diagram of subjects included in the cross-sectional analysis of the Australian National Nutrition and Physical Activity Survey. *Individuals with missing data for estimation of energy misreporting (i.e. ratio of energy intake: predicted total energy expenditure) were excluded.
Obesity-DP1 was positively associated with intakes of fruits and vegetables and low-fat milk and negatively associated with non-whole-grain bread, high energy-containing beverages and snacks, and processed meat intake. Higher Obesity-DP2 was associated with higher high-sugar and high-fat foods and beverage consumption and lower consumption of vegetables, wine, whole-grain bread and non-whole-grain cereals (Table 2).

Hypertension-related dietary patterns. Hypertension-DP1 was positively correlated with Na:K $(r$ 0.54) and SFA:PUFA $(r 0.42)$ and negatively correlated with fibre density $(r-0.73)$. In contrast, Hypertension-DP2 was positively correlated with SFA:PUFA $(r \quad 0.47)$ and negatively correlated with $\mathrm{Na}: \mathrm{K}$ $(r-0 \cdot 40$; Table 1$)$.

Hypertension-DP1 was characterised by a high consumption of non-whole-grain bread, processed meat and savoury pies and high energy-containing beverages and a low consumption of whole-grain cereals, fruits and vegetables, and nuts and seeds. In contrast, Hypertension-DP2 was positively associated with consumption of high SFA-containing foods and beverages and starchy vegetables, and negatively associated with consumption of high unsaturated fat-containing foods, non-wholegrain bread, fried foods, fish and fruit drinks (Table 3).

\section{Dietary patterns and demographic characteristics}

Demographic characteristics of participants by tertile of DP are summarised in Tables 4 and 5 for obesity- and hypertensionrelated DP, respectively.

Obesity-related dietary patterns. Individuals with a higher Obesity-DP1 were older, non-smokers, more highly educated and more individuals met physical activity recommendations. In contrast, individuals with a higher Obesity-DP2 were younger, current smokers, spent more time sedentary and were obese (Table 4).

Hypertension-related dietary patterns. Individuals with a higher Hypertension-DP1 were younger, current smokers, with less individuals meeting physical activity recommendations and spending more time sedentary. In contrast, individuals with a higher Hypertension-DP2 were older and more highly educated (Table 5).

\section{Dietary patterns and prevalence of obesity and hypertension}

Overweight and obesity prevalence. As shown in Table 6, individuals in the highest tertile of DP1 had a lower prevalence of overweight or obesity compared with those in the lowest tertile (PR 0.88; $95 \%$ CI 0.81, 0.95; $P=0.003$ ). When stratified by sex, both males and females had a lower prevalence of overweight or obesity (PR 0.90; 95\% CI 0.81, 0.99; $P=0.048$ and PR 0.86; 95\% CI 0.77, 0.97; $P=0.016$, respectively), whereas when stratified by age group only individuals in the highest tertile of Obesity-DP1 and $<50$ years had a lower prevalence of overweight or obesity (PR 0.83; $95 \%$ CI 0.74, 0.94; $P=0.003$ ). Individuals in the highest tertile of Obesity-DP2 had a higher 
Table 1. Explained variation (\%) in food intakes and response variables for each dietary pattern (DP) as assessed using reduced rank regression and correlation coefficient between DP and response variables for obesity and hypertension-related outcomes ( $n$ 4908)

\begin{tabular}{|c|c|c|c|c|c|c|c|c|}
\hline \multirow{2}{*}{$\begin{array}{l}\text { DP } \\
\text { Obesity }\end{array}$} & \multicolumn{5}{|c|}{ Explained variation (\%) } & \multicolumn{3}{|c|}{ Correlation coefficient } \\
\hline & $\begin{array}{l}\text { Food intakes } \\
\text { (total) }\end{array}$ & $\begin{array}{l}\text { Responses } \\
\text { (total) }\end{array}$ & $\begin{array}{c}\text { DED } \\
(\mathrm{kJ} / 100 \mathrm{~g})\end{array}$ & $\begin{array}{l}\text { Fibre density } \\
\text { (g/MJ) }\end{array}$ & $\begin{array}{c}\text { Sugars } \\
(\% \mathrm{E})\end{array}$ & $\begin{array}{c}\text { DED } \\
(\mathrm{kJ} / 100 \mathrm{~g})\end{array}$ & $\begin{array}{l}\text { Fibre density } \\
\text { (g/MJ) }\end{array}$ & $\begin{array}{c}\text { Sugars } \\
(\% \mathrm{E})\end{array}$ \\
\hline Obesity-DP1 & 3.98 & $36 \cdot 4$ & $56 \cdot 0$ & 46.9 & $6 \cdot 24$ & $-0.79^{\star \star \star}$ & $0.69^{\star \star *}$ & $0.24^{\star \star \star}$ \\
\hline Obesity-DP2 & $2 \cdot 67$ & $18 \cdot 0$ & $56 \cdot 1$ & $51 \cdot 4$ & 55.5 & 0.05 & $-0 \cdot 24^{\star \star \star}$ & $0.69^{\star \star \star}$ \\
\hline \multirow[t]{2}{*}{ Obesity-DP3 } & 1.98 & 9.57 & $70 \cdot 0$ & $65 \cdot 4$ & $56 \cdot 3$ & $0.36^{\star * *}$ & $0.39^{\star \star \star}$ & $0.06^{* *}$ \\
\hline & \multicolumn{5}{|c|}{ Explained variation (\%) } & \multicolumn{3}{|c|}{ Correlation coefficient } \\
\hline Hypertension & $\begin{array}{l}\text { Food intakes } \\
\text { (total) }\end{array}$ & $\begin{array}{c}\text { Responses } \\
\text { (total) }\end{array}$ & $\begin{array}{l}\text { Fibre density } \\
\text { (g/MJ) }\end{array}$ & $\mathrm{Na}: \mathrm{K}$ & $\begin{array}{l}\text { SFA: } \\
\text { PUFA }\end{array}$ & $\begin{array}{c}\text { Fibre density } \\
\text { (g/MJ) }\end{array}$ & $\mathrm{Na}: \mathrm{K}$ & $\begin{array}{l}\text { SFA: } \\
\text { PUFA }\end{array}$ \\
\hline Hypertension-DP1 & 4.43 & 33.3 & $52 \cdot 4$ & $30 \cdot 2$ & $17 \cdot 3$ & $-0.73^{\star \star *}$ & $0.54^{\star \star \star}$ & $0.42^{* \star *}$ \\
\hline Hypertension-DP2 & $2 \cdot 32$ & $12 \cdot 6$ & 52.5 & $45 \cdot 9$ & 39.4 & -0.05 & $-0.40^{\star \star *}$ & $0.47^{\star \star \star}$ \\
\hline Hypertension-DP3 & $2 \cdot 08$ & 9.06 & $65 \cdot 4$ & 53.6 & $46 \cdot 0$ & $0.38^{\star \star \star}$ & $0.28^{\star \star \star}$ & $0.24^{\star \star \star}$ \\
\hline
\end{tabular}

DED, dietary energy density; \%E, percentage of energy intake.

*** Correlation coefficient is significant at $P<0.001$.

Table 2. Intakes of response variables and key foods across sex-specific tertiles (T) of dietary pattern (DP) for obesity outcomes (Mean values with their standard errors; $n$ 4908)

\begin{tabular}{|c|c|c|c|c|c|c|c|c|}
\hline \multirow[b]{3}{*}{ Food groups } & \multirow[b]{3}{*}{ Factor loading } & \multicolumn{6}{|c|}{ Tertile of DP } & \multirow[b]{3}{*}{$P_{\text {trend }}{ }^{*}$} \\
\hline & & \multicolumn{2}{|c|}{ T1 } & \multicolumn{2}{|c|}{$\mathrm{T} 2$} & \multicolumn{2}{|c|}{ Т3 } & \\
\hline & & Mean & SE & Mean & SE & Mean & SE & \\
\hline \multicolumn{9}{|l|}{ Obesity-DP1 } \\
\hline \multicolumn{9}{|l|}{ Response variables } \\
\hline DED (kJ/100 g) & - & 747 & 4.36 & 615 & 3.08 & 514 & 2.98 & $<0.001$ \\
\hline Fibre density (g/MJ) & - & 2.03 & 0.03 & $2 \cdot 74$ & 0.03 & 3.57 & 0.04 & $<0.001$ \\
\hline Sugar (\%E) & - & $17 \cdot 1$ & 0.29 & $18 \cdot 7$ & 0.24 & 20.7 & 0.23 & $<0.001$ \\
\hline \multicolumn{9}{|l|}{ Direct associations (g/d) } \\
\hline Apples and pears & 0.30 & 18 & 2 & 37 & 2 & 87 & 4 & $<0.001$ \\
\hline Carrots & 0.24 & 10 & 1 & 16 & 1 & 38 & 2 & $<0.001$ \\
\hline Low-fat milk & 0.22 & 50 & 6 & 84 & 5 & 146 & 8 & $<0.001$ \\
\hline Tropical fruit & 0.22 & 17 & 1 & 29 & 2 & 55 & 4 & $<0.001$ \\
\hline Brassica vegetables & 0.20 & 18 & 1 & 24 & 1 & 39 & 2 & $<0.001$ \\
\hline \multicolumn{9}{|l|}{ Inverse associations } \\
\hline Non-whole-grain bread & -0.29 & 78 & 2 & 51 & 2 & 36 & 2 & $<0.001$ \\
\hline Fruit drinks & -0.20 & 298 & 21 & 172 & 10 & 98 & 6 & $<0.001$ \\
\hline Beer and cider & -0.20 & 282 & 21 & 99 & 10 & 77 & 9 & $<0.001$ \\
\hline Processed meat & -0.18 & 42 & 2 & 27 & 1 & 18 & 1 & $<0.001$ \\
\hline Snacks & -0.17 & 8 & 1 & 3 & 1 & 2 & 1 & $<0.001$ \\
\hline \multicolumn{9}{|l|}{ Obesity-DP2 } \\
\hline \multicolumn{9}{|l|}{ Response variables } \\
\hline DED (kJ/100 g) & - & 628 & 4.61 & 615 & 5.51 & 633 & $6 \cdot 27$ & 0.89 \\
\hline Fibre density (g/MJ) & - & 2.98 & 0.04 & $2 \cdot 88$ & 0.04 & 2.47 & 0.03 & $<0.001$ \\
\hline Sugar $(\% \mathrm{E})$ & - & $13 \cdot 0$ & $0 \cdot 16$ & $18 \cdot 7$ & 0.17 & $24 \cdot 7$ & 0.32 & $<0.001$ \\
\hline \multicolumn{9}{|l|}{ Direct associations $(\mathrm{g} / \mathrm{d})$} \\
\hline Fruit drinks & 0.43 & 65 & 5 & 135 & 8 & 369 & 20 & $<0.001$ \\
\hline Sugar rich foods & 0.44 & 9 & 1 & 15 & 1 & 31 & 2 & $<0.001$ \\
\hline Chocolate & 0.24 & 3 & 1 & 5 & 1 & 11 & 1 & $<0.001$ \\
\hline Cream & 0.21 & 11 & 1 & 17 & 1 & 36 & 3 & $<0.001$ \\
\hline Full-fat milk & 0.21 & 96 & 4 & 126 & 6 & 184 & 10 & $<0.001$ \\
\hline \multicolumn{9}{|l|}{ Inverse associations (g/d) } \\
\hline Non-whole-grain cereals & -0.19 & 126 & 6 & 82 & 4 & 66 & 4 & $<0.001$ \\
\hline Wine & -0.21 & 78 & 5 & 47 & 2 & 37 & 2 & $<0.001$ \\
\hline Brassica vegetables & -0.17 & 39 & 2 & 23 & 1 & 19 & 1 & $<0.001$ \\
\hline Mixed vegetables & -0.16 & 125 & 8 & 50 & 4 & 33 & 6 & $<0.001$ \\
\hline Whole-grain bread & -0.16 & 60 & 3 & 37 & 2 & 31 & 1 & $<0.001$ \\
\hline
\end{tabular}

DED, dietary energy density; \%E, percentage of energy intake.

${ }^{\star}$ Linear regression analyses tested for trends across tertiles of DP. Analyses were adjusted for age and sex. 
Table 3. Intakes of response variables and key foods across sex-specific tertiles (T) of dietary pattern (DP) for hypertension outcomes (Mean values with their standard errors; $n$ 4908)

\begin{tabular}{|c|c|c|c|c|c|c|c|c|}
\hline \multirow[b]{3}{*}{ Food groups } & \multirow[b]{3}{*}{ Factor loading } & \multicolumn{6}{|c|}{ Tertile of DP } & \multirow[b]{3}{*}{$P_{\text {trend }}{ }^{*}$} \\
\hline & & \multicolumn{2}{|c|}{$\mathrm{T} 1$} & \multicolumn{2}{|c|}{$\mathrm{T} 2$} & \multicolumn{2}{|c|}{ T3 } & \\
\hline & & Mean & SE & Mean & SE & Mean & SE & \\
\hline \multicolumn{9}{|l|}{ Hypertension-DP1 } \\
\hline \multicolumn{9}{|l|}{ Response variables } \\
\hline Fibre density (g/MJ) & - & 3.65 & 0.32 & 2.68 & 0.23 & 1.99 & 0.03 & $<0.001$ \\
\hline $\mathrm{Na}: \mathrm{K}$ ratio & - & 0.64 & 0.01 & 0.84 & 0.01 & $1 \cdot 14$ & 0.02 & $<0.001$ \\
\hline SFA:PUFA ratio & - & $2 \cdot 13$ & 0.04 & 2.78 & 0.05 & 3.43 & 0.06 & $<0.001$ \\
\hline \multicolumn{9}{|l|}{ Direct associations (g/d) } \\
\hline Non-whole-grain bread & 0.30 & 33 & 2 & 51 & 2 & 81 & 2 & $<0.001$ \\
\hline Processed meat & 0.28 & 14 & 1 & 23 & 1 & 50 & 3 & $<0.001$ \\
\hline Fruit drink & 0.26 & 86 & 6 & 144 & 7 & 338 & 21 & $<0.001$ \\
\hline Savoury pies & 0.20 & 7 & 1 & 14 & 2 & 32 & 2 & $<0.001$ \\
\hline Beer and cider & 0.15 & 90 & 11 & 123 & 13 & 246 & 23 & $<0.001$ \\
\hline \multicolumn{9}{|l|}{ Inverse associations (g/d) } \\
\hline Apples and pears & $-0 \cdot 25$ & 86 & 4 & 37 & 2 & 12 & 1 & $<0.001$ \\
\hline Whole-grain cereal & $-0 \cdot 24$ & 37 & 2 & 20 & 1 & 23 & 2 & $<0.001$ \\
\hline Carrots & -0.22 & 37 & 2 & 17 & 1 & 10 & $\overline{1}$ & $<0.001$ \\
\hline Nuts and seeds & -0.20 & 14 & 1 & 6 & 1 & 4 & 1 & $<0.001$ \\
\hline Brassica vegetables & $-0 \cdot 19$ & 40 & 3 & 24 & 1 & 17 & 1 & $<0.001$ \\
\hline \multicolumn{9}{|l|}{ Hypertension-DP2 } \\
\hline \multicolumn{9}{|l|}{ Response variables } \\
\hline Fibre density (g/MJ) & - & $2 \cdot 77$ & 0.04 & $2 \cdot 84$ & 0.04 & $2 \cdot 71$ & 0.04 & 0.038 \\
\hline $\mathrm{Na}$ K K ratio & - & 1.06 & 0.02 & 0.86 & 0.01 & 0.69 & 0.01 & $<0.001$ \\
\hline SFA:PUFA ratio & - & 2.09 & 0.04 & 2.70 & 0.05 & 3.56 & 0.05 & $<0.001$ \\
\hline \multicolumn{9}{|l|}{ Direct associations (g/d) } \\
\hline Full-fat milk & 0.39 & 76 & 4 & 119 & 7 & 212 & 9 & $<0.001$ \\
\hline Chocolate & 0.30 & 3 & 1 & 4 & 1 & 13 & 1 & $<0.001$ \\
\hline Cream & 0.30 & 10 & 1 & 14 & 1 & 41 & 3 & $<0.001$ \\
\hline Starchy vegetables & 0.30 & 26 & 2 & 43 & 2 & 76 & 3 & $<0.001$ \\
\hline Saturated fat-rich foods & 0.24 & 1 & 1 & 2 & 1 & 4 & 1 & $<0.001$ \\
\hline \multicolumn{9}{|l|}{ Inverse associations (g/d) } \\
\hline Unsaturated fat-rich foods & -0.25 & 7 & 1 & 4 & 1 & 4 & 1 & $<0.001$ \\
\hline Non-whole-grain bread & $-0 \cdot 24$ & 72 & 3 & 50 & 2 & 44 & 2 & $<0.001$ \\
\hline Fried food & $-0 \cdot 19$ & 25 & 2 & 9 & 1 & 8 & 1 & $<0.001$ \\
\hline Fish & $-0 \cdot 19$ & 34 & 3 & 23 & 2 & 13 & 1 & $<0.001$ \\
\hline Fruit drinks & -0.18 & 267 & 17 & 160 & 9 & 141 & 10 & $<0.001$ \\
\hline
\end{tabular}

* Linear regression analyses tested for trends across tertiles of DP. Analyses were adjusted for age and sex.

prevalence of overweight or obesity (PR 1.09; 95\% CI 1.01, $1 \cdot 18 ; P=0.035)$, and when stratified by sex this was only significant in females (PR 1.16; $95 \%$ CI 1.01, 1.32; $P=0.037$ ).

Prevalence of central adiposity was higher in individuals in the highest tertile of Obesity-DP1 (PR 0.85; 95\% CI 0.79, 0.92; $P<0.001$ ), which was evident in both males and females (PR 0.83; 95\% CI 0.73, 0.94; $P=0.008$ and PR 0.87; 95\% CI 0.80, 0.95; $P=0.002$, respectively). Individuals $<50$ years in the highest tertile of Obesity-DP1 compared with the lowest tertile had lower prevalence of central adiposity (PR 0.84; 95\% CI 0.75, 0.95; $P=0.006$ ). Prevalence of central adiposity was higher in males only in the highest tertile of Obesity-DP2 compared with the lowest tertile (PR 1.16; $95 \%$ CI 1.05, 1.29; $P=0.005$; Table 5).

Hypertension prevalence. There was a trend towards higher prevalence of hypertension among individuals in the highest tertile of Hypertension-DP1 (PR 1.18; 95\% CI 0.99, 1.41; $P=0.055)$ compared with the lowest. When stratified by sex, men in the highest tertile of DP1 had a higher prevalence of hypertension than those in the lowest tertile (PR 1.32; $95 \% \mathrm{CI}$ $1.03,1.68 ; P=0.026)$. Furthermore, prevalence of hypertension was higher in overweight or obese individuals with the highest Hypertension-DP1 compared with the lowest (PR 1.26; $95 \%$ CI
1.02, 1.55; $P=0.034)$. Hypertension-DP2 was not associated with prevalence of hypertension (Table 6).

Sensitivity analyses. Comparison of factor loadings for DP derived from the total sample and from the $50 \%$ split sample showed similar factor loadings (online Supplementary Table S2). For obesity outcomes, following inclusion of only foods that had a factor loading of $\geq 0 \cdot 17$, Obesity-DP1 was no longer significantly associated with obesity and prevalence of obesity was no longer significant in individuals $<50$ years of age. All other patterns of significant results for obesityassociated outcomes remained unchanged in Obesity-DP1. Prevalence of central adiposity became significantly positively associated with Obesity-DP2, with the pattern of significant results remaining unchanged for all other obesity and adiposityassociated outcomes. For hypertension outcomes, the pattern of significant results was consistent for both Hypertension-DP1 and Hypertension-DP2 (data not shown).

To further investigate energy misreporting, energy misreporters were identified (under-reporters: $n$ 1328; over-reporters: $n$ 524), and analyses were run with and without individuals who misreported their energy intakes (online Supplementary Table S1). The direction of the relationships remained 


\section{NS British Journal of Nutrition}

Table 4. Demographic characteristics across sex-specific tertiles (T) of obesity-related dietary patterns (DP)*

\begin{tabular}{|c|c|c|c|c|c|c|c|c|c|}
\hline \multirow[b]{3}{*}{ Characteristics } & & & \multicolumn{6}{|c|}{ Obesity DP } & \multirow[b]{3}{*}{$P_{\text {trend }} \dagger$} \\
\hline & \multicolumn{2}{|c|}{ All } & \multicolumn{2}{|c|}{$\mathrm{T} 1$} & \multicolumn{2}{|c|}{ T2 } & \multicolumn{2}{|c|}{ Т3 } & \\
\hline & Mean & $\mathrm{SE}$ & Mean & $\mathrm{SE}$ & Mean & $\mathrm{SE}$ & Mean & SE & \\
\hline \multicolumn{10}{|l|}{ Obesity-DP1 } \\
\hline DP & \multicolumn{2}{|c|}{ _- } & $-1 \cdot 28$ & 0.03 & -0.09 & 0.01 & 1.24 & 0.03 & $<0.001$ \\
\hline Age (years) & \multirow{2}{*}{\multicolumn{2}{|c|}{$47 \cdot 8$}} & 42.5 & 0.55 & 46.5 & 0.52 & $49 \cdot 0$ & 0.57 & $<0.001$ \\
\hline Female (\%) & & & \multicolumn{2}{|c|}{47.9} & \multicolumn{2}{|c|}{$47 \cdot 8$} & \multirow{2}{*}{\multicolumn{2}{|c|}{$47 \cdot 8$}} & 0.99 \\
\hline Highest level of education (\%) & & & & & & & & & \\
\hline Low & \multicolumn{2}{|c|}{$23 \cdot 4$} & \multicolumn{2}{|c|}{23.1} & \multicolumn{2}{|c|}{29.8} & \multicolumn{2}{|c|}{$30 \cdot 7$} & 0.010 \\
\hline Medium & \multirow{2}{*}{\multicolumn{2}{|c|}{$\begin{array}{l}48.8 \\
27.8\end{array}$}} & \multicolumn{2}{|c|}{$38 \cdot 1$} & \multicolumn{2}{|c|}{31.9} & \multicolumn{2}{|c|}{$34 \cdot 1$} & \\
\hline High & & & & & & & & & \\
\hline \multicolumn{10}{|l|}{ Smoking (\%) } \\
\hline Never smoked & \multicolumn{2}{|c|}{$16 \cdot 7$} & & & & & & & $<0.001$ \\
\hline Former smoker & & & & & & & & & \\
\hline Current smoker & & & & & & & & & \\
\hline Meet PA recommendations (\%) & & & & & & & & & 0.001 \\
\hline Sedentary behaviour $(\mathrm{min} / \mathrm{d})$ & 339 & $4 \cdot 37$ & 352 & $7 \cdot 11$ & 334 & $7 \cdot 61$ & 332 & $7 \cdot 77$ & 0.08 \\
\hline $\mathrm{BMI}\left(\mathrm{kg} / \mathrm{m}^{2}\right)$ & 27.3 & $0 \cdot 12$ & 27.5 & 0.23 & $27 \cdot 1$ & 0.20 & 27.4 & 0.22 & 0.94 \\
\hline BMI category (\%) & & & & & & & & & \\
\hline Underweight/normal weight & & & & & & & & & 0.80 \\
\hline Overweight & & & & & & & & & \\
\hline Obese & & & & & & & & & \\
\hline Waist circumference $(\mathrm{cm})$ & 92.7 & 0.32 & 93.4 & 0.64 & $92 \cdot 0$ & 0.53 & $92 \cdot 7$ & 0.62 & 0.62 \\
\hline Obesity-DP2 & & & & & & & & & \\
\hline DP & & & -1.08 & 0.02 & -0.09 & 0.01 & $1 \cdot 10$ & 0.03 & $<0.001$ \\
\hline Age (years) & $46 \cdot 0$ & 0.20 & $47 \cdot 3$ & 0.58 & $47 \cdot 0$ & 0.64 & $43 \cdot 6$ & 0.62 & $<0.001$ \\
\hline Female (\%) & & & & & & & & & 0.99 \\
\hline Highest level of education (\%) & & & & & & & & & \\
\hline Low & & & & & & & & & 0.13 \\
\hline Medium & & & & & & & & & \\
\hline High & & & & & & & & & \\
\hline Smoking (\%) & & & & & & & & & \\
\hline Never smoked & & & & & & & & & 0.010 \\
\hline Former smoker & & & & & & & & & \\
\hline Current smoker & & & & & & & & & \\
\hline Meet PA recommendations (\%) & & & & & & & & & 0.45 \\
\hline Sedentary behaviour $(\mathrm{min} / \mathrm{d})$ & 339 & $4 \cdot 37$ & 323 & 8.75 & 340 & $7 \cdot 31$ & 355 & 5.54 & 0.001 \\
\hline $\mathrm{BMI}\left(\mathrm{kg} / \mathrm{m}^{2}\right)$ & $27 \cdot 3$ & 0.12 & 26.9 & 0.20 & 27.6 & 0.22 & 27.5 & 0.20 & 0.07 \\
\hline BMI category (\%) & & & & & & & & & \\
\hline Underweight/normal weight & & & & & & & & & 0.008 \\
\hline Overweight & & & & & & & & & \\
\hline Obese & & & & & & & & & \\
\hline Waist circumference $(\mathrm{cm})$ & $92 \cdot 7$ & 0.32 & $92 \cdot 1$ & 0.58 & 93.2 & 0.62 & $92 \cdot 7$ & 0.52 & 0.54 \\
\hline
\end{tabular}

* Education: low (completed some high school or less), medium (completed high school or completed some high school and/or certificate/diploma) and high (having a tertiary qualification). BMI category: underweight/normal weight

† Linear regression analyses (continuous variables) and $\chi^{2}$ (categorical variables) were used to test for trends across tertiles. 
Table 5. Demographic characteristics across sex-specific tertiles $(T)$ of hypertension-related dietary patterns (DP)* (Mean value with their standard errors; $n$ 4908)

\begin{tabular}{|c|c|c|c|c|c|c|c|c|c|c|}
\hline \multirow[b]{3}{*}{ Characteristics } & \multicolumn{9}{|c|}{ Hypertension DP } & \multirow[b]{3}{*}{$P_{\text {trend }} \dagger$} \\
\hline & \multicolumn{3}{|c|}{$\mathrm{T} 1$} & \multicolumn{3}{|c|}{$\mathrm{T} 2$} & \multicolumn{3}{|c|}{ T3 } & \\
\hline & Mean & & SE & Mean & & $\mathrm{SE}$ & Mean & & $\mathrm{SE}$ & \\
\hline \multicolumn{11}{|l|}{ Hypertension-DP1 } \\
\hline DP & -1.40 & & 0.03 & 0.09 & & 0.01 & $\begin{array}{r}1.40 \\
41.3\end{array}$ & & $\begin{array}{l}0.03 \\
0.48\end{array}$ & $<0.001$ \\
\hline $\begin{array}{l}\text { Age (years) } \\
\text { Female (\%) }\end{array}$ & 49.5 & $47 \cdot 8$ & 0.59 & $47 \cdot 2$ & 47.8 & 0.61 & $41 \cdot 3$ & $47 \cdot 8$ & 0.48 & $\begin{array}{c}<0.001 \\
0.99\end{array}$ \\
\hline Highest level of education (\%) & & & & & & & & & & \\
\hline Low & & $23 \cdot 3$ & & & $23 \cdot 8$ & & & $23 \cdot 1$ & & 0.028 \\
\hline Medium & & 45.8 & & & $47 \cdot 3$ & & & $53 \cdot 2$ & & \\
\hline High & & 30.9 & & & 28.9 & & & 23.7 & & \\
\hline \multicolumn{11}{|l|}{ Smoking (\%) } \\
\hline Never smoked & & $10 \cdot 2$ & & & $15 \cdot 5$ & & & $24 \cdot 4$ & & $<0.001$ \\
\hline Former smoker & & 33.0 & & & $35 \cdot 8$ & & & $26 \cdot 0$ & & \\
\hline Current smoker & & 56.9 & & & 48.8 & & & 50.0 & & \\
\hline Meet PA recommendations (\%) & & 52.2 & & & $43 \cdot 1$ & & & 41.5 & & $<0.001$ \\
\hline Sedentary behaviour $(\mathrm{min} / \mathrm{d})$ & 326 & & 7.50 & 330 & & $\begin{array}{l}7.28 \\
0.22\end{array}$ & 362 & & 7.47 & 0.002 \\
\hline $\mathrm{BMI}\left(\mathrm{kg} / \mathrm{m}^{2}\right)$ & 27.0 & & 0.20 & 27.5 & & 0.22 & 27.6 & & 0.24 & 0.14 \\
\hline BMI category (\%) & & & & & & & & & & \\
\hline Underweight/normal weight & & $37 \cdot 3$ & & & 36.8 & & & 38.2 & & 0.028 \\
\hline Overweight & & $36 \cdot 3$ & & & $36 \cdot 3$ & & & 32.8 & & \\
\hline Obese & & $22 \cdot 2$ & & & $26 \cdot 9$ & & & 29.1 & & \\
\hline Waist circumference $(\mathrm{cm})$ & $91 \cdot 8$ & & 0.57 & 93.3 & & 0.57 & 93.1 & & 0.57 & 0.21 \\
\hline Systolic blood pressure (mmHg) & 123.1 & & 0.61 & 123.4 & & 0.85 & 121.5 & & 0.70 & 0.09 \\
\hline Diastolic blood pressure (mmHg) & 75.9 & & 0.37 & $77 \cdot 2$ & & 0.47 & 76.6 & & 0.38 & 0.22 \\
\hline Hypertension (\%) & & $20 \cdot 6$ & & & $24 \cdot 4$ & & & $20 \cdot 0$ & & 0.06 \\
\hline \multicolumn{11}{|l|}{ Hypertension-DP2 } \\
\hline DP & -1.08 & & 0.02 & -0.11 & & 0.01 & 1.01 & & 0.02 & $<0.001$ \\
\hline Age (years) & 43.7 & & 0.55 & $47 \cdot 1$ & & 0.59 & 47.3 & & 0.56 & $<0.001$ \\
\hline \multirow{2}{*}{\multicolumn{11}{|c|}{ Highest level of education (\%) }} \\
\hline & & & & & & & & & & \\
\hline Low & & 22.5 & & & $24 \cdot 4$ & & & 23.4 & & 0.016 \\
\hline Medium & & 52.7 & & & 44.6 & & & 48.8 & & 0.0 \\
\hline High & & 24.8 & & & 31.1 & & & 27.8 & & \\
\hline Smoking (\%) & & 17.8 & & & 15.9 & & & 16.7 & & 0.28 \\
\hline Never smoked & & $29 \cdot 6$ & & & $34 \cdot 3$ & & & 30.9 & & \\
\hline Former smoker & & 52.6 & & & 49.9 & & & 52.7 & & \\
\hline \multicolumn{11}{|l|}{ Current smoker } \\
\hline Meet PA recommendations (\%) & & 44.0 & & & $47 \cdot 3$ & & & 45.5 & & 0.34 \\
\hline Sedentary behaviour $(\mathrm{min} / \mathrm{d})$ & 330 & & 7.30 & 346 & & 7.46 & 342 & & 7.50 & 0.27 \\
\hline $\mathrm{BMI}\left(\mathrm{kg} / \mathrm{m}^{2}\right)$ & 27.3 & & 0.22 & 27.5 & & 0.19 & 27.2 & & 0.21 & 0.60 \\
\hline BMI category $(\%)$ & & & & & & & & & & \\
\hline Underweight/normal weight & & $37 \cdot 3$ & & & $35 \cdot 2$ & & & 39.9 & & 0.26 \\
\hline Overweight & & $36 \cdot 3$ & & & 39.0 & & & 34.3 & & \\
\hline Obese & & $26 \cdot 5$ & & & $25 \cdot 8$ & & & 25.9 & & \\
\hline Waist circumference $(\mathrm{cm})$ & 92.6 & & 0.59 & 93.1 & & 0.50 & $92 \cdot 3$ & & 0.52 & 0.73 \\
\hline Systolic blood pressure (mmHg) & $121 \cdot 7$ & & 0.63 & 123.8 & & 0.73 & 122.4 & & 0.59 & 0.44 \\
\hline Diastolic blood pressure (mmHg) & 76.4 & & 0.44 & $77 \cdot 3$ & & 0.47 & $76 \cdot 0$ & & 0.31 & 0.43 \\
\hline Hypertension (\%) & & 21.0 & & & 22.9 & & & $21 \cdot 2$ & & 0.61 \\
\hline
\end{tabular}

* Education: low (completed some high school or less), medium (completed high school or completed some high school and/or certificate/diploma) and high (having a tertiary qualification). BMl category: underweight/normal weight $\left(\mathrm{BMl}<25 \mathrm{~kg} / \mathrm{m}^{2}\right)$, overweight $\left(25 \leq \mathrm{BMl}<30 \mathrm{~kg} / \mathrm{m}^{2}\right)$, obese $\left(\mathrm{BMl} \geq 30 \mathrm{~kg} / \mathrm{m}^{2}\right) ;$ hypertensive: $\geq 140 / 90 \mathrm{mmHg} ; \mathrm{PA}$, physical activity.

† Linear regression analyses (continuous variables) and $\chi^{2}$ (categorical variables) were used to test for trends across tertiles.

comparable; however, the pattern of significant results changed. To examine intra-person variation, DP were derived for obesity and hypertension outcomes on the basis of usual intakes, day 1 and day 2, respectively. Patterns of results were consistent between methods (online Supplementary Table S3).

\section{Discussion}

\section{Main findings}

The present study identified two DP associated with DED, fibre density and sugar intakes and a DP associated with Na:K, SFA: PUFA ratio and fibre density. Our main findings are that a DP characterised by low DED, high fibre density and high sugar intakes (from fruits) was associated with lower prevalence of overweight or obesity, whereas a DP with low fibre density and high sugar intake (from chocolate and fruit drinks) was associated with higher prevalence of overweight or obesity. Furthermore, we identified that a DP characterised by low fibre density and high $\mathrm{Na}$ : $\mathrm{K}$ and high SFA:PUFA ratio was associated with higher prevalence hypertension. Our study is the first to show that RRR-derived DP based on WHO dietary recommendations are related to obesity and hypertension in a nationally representative adult population. Our findings also suggest that there are many differential obesogenic effects between two high-sugar diets, one which is high in fruits (natural sugars) and fibre and the other high in chocolate and fruit drinks (added sugars).

\section{Comparison with other studies}

Although no study to date has used DED, fibre density and percentage energy from sugars as response variables in RRR for obesity outcomes, an analysis in adolescents from the 1995 Australian National Nutrition Survey produced a DP high in sugar and fat and low in fibre and did not identify any significant associations with obesity or hypertension ${ }^{(34)}$. 
Table 6. Obesity and hypertension prevalence ratio (PR) across sex-specific tertiles ( $\mathrm{T}$ ) of dietary pattern (DP) stratified by sex, age and BMl group (Prevalence ratios and 95 confidence intervals; $n$ 4908)

\begin{tabular}{|c|c|c|c|c|c|c|}
\hline \multirow[b]{3}{*}{ Characteristics } & \multicolumn{5}{|c|}{ Tertile of DP } & \multirow[b]{3}{*}{$P_{\text {trend }}{ }^{*}$} \\
\hline & \multirow[b]{2}{*}{$\mathrm{T} 1$} & \multicolumn{2}{|c|}{$\mathrm{T} 2$} & \multicolumn{2}{|c|}{ T3 } & \\
\hline & & PR & $95 \% \mathrm{Cl}$ & PR & $95 \% \mathrm{Cl}$ & \\
\hline \multicolumn{7}{|l|}{ Overweight and obesity $\dagger$} \\
\hline \multicolumn{7}{|l|}{ Obesity-DP1 } \\
\hline All subjects & $1 \cdot 0$ & 0.86 & $0.79,0.93$ & 0.88 & $0.81,0.95$ & 0.003 \\
\hline Males & 1.0 & 0.88 & $0.79,0.97$ & 0.90 & $0.81,0.99$ & 0.048 \\
\hline Females & $1 \cdot 0$ & 0.83 & $0.72,0.95$ & 0.86 & $0.77,0.97$ & 0.016 \\
\hline Age $<50$ years & 1.0 & 0.83 & $0.73,0.96$ & 0.83 & $0.74,0.94$ & 0.003 \\
\hline Age $\geq 50$ years & 1.0 & 0.91 & $0.83,0.99$ & 0.95 & $0.87,1.05$ & 0.45 \\
\hline \multicolumn{7}{|l|}{ Obesity-DP2 } \\
\hline All subjects & 1.0 & 1.05 & $0.97,1.14$ & 1.09 & $1 \cdot 01,1 \cdot 18$ & 0.035 \\
\hline Males & 1.0 & 1.04 & $0.96,1.13$ & 1.06 & $0.99,1.14$ & 0.09 \\
\hline Females & 1.0 & 1.06 & $0.93,1.21$ & $1 \cdot 16$ & $1.01,1.32$ & 0.037 \\
\hline Age $<50$ years & 1.0 & $1 \cdot 10$ & $0.97,1.26$ & $1 \cdot 13$ & $0.98,1.30$ & 0.09 \\
\hline Age $\geq 50$ years & 1.0 & 1.02 & $0.92,1.12$ & 1.04 & $0.93,1.16$ & 0.51 \\
\hline \multicolumn{7}{|l|}{ Central adiposity } \\
\hline \multicolumn{7}{|l|}{ Obesity-DP1 } \\
\hline All subjects & 1.0 & 0.86 & $0.78,0.94$ & 0.85 & $0.79,0.92$ & $<0.001$ \\
\hline Males & 1.0 & 0.84 & $0.73,0.95$ & 0.83 & $0.73,0.94$ & 0.008 \\
\hline Females & 1.0 & 0.87 & $0.77,0.97$ & 0.87 & $0.80,0.95$ & 0.002 \\
\hline Age $<50$ years & 1.0 & 0.85 & $0.74,0.98$ & 0.84 & $0.75,0.95$ & 0.006 \\
\hline Age $\geq 50$ years & 1.0 & 0.91 & $0.83,1.00$ & 0.93 & $0.86,1.01$ & 0.15 \\
\hline \multicolumn{7}{|l|}{ Obesity-DP2 } \\
\hline All subjects & 1.0 & 0.97 & $0.90,1.05$ & 1.07 & $1 \cdot 00,1 \cdot 16$ & 0.06 \\
\hline Males & 1.0 & 0.99 & $0.88,1.12$ & $1 \cdot 16$ & $1.05,1.29$ & 0.005 \\
\hline Females & 1.0 & 0.96 & $0.87,1.05$ & 0.99 & $0.91,1.08$ & 0.86 \\
\hline Age $<50$ years & 1.0 & 0.94 & $0.84,1.06$ & 1.08 & $0.97,1.21$ & 0.14 \\
\hline Age $\geq 50$ years & 1.0 & 1.02 & $0.92,1.12$ & 1.02 & $0.92,1.14$ & 0.71 \\
\hline \multicolumn{7}{|l|}{ Hypertension } \\
\hline \multicolumn{7}{|l|}{ Hypertension-DP1 } \\
\hline All subjects & 1.0 & 1.20 & $0.98,1.46$ & $1 \cdot 18$ & $0.99,1.41$ & 0.055 \\
\hline Males & 1.0 & $1 \cdot 18$ & $0.91,1.53$ & 1.32 & $1.03,1.68$ & 0.026 \\
\hline Females & 1.0 & 1.24 & $0.95,1.62$ & 1.04 & $0.79,1.37$ & 0.67 \\
\hline Age $<50$ years & 1.0 & 1.15 & $0.78,1.69$ & 1.20 & $0.81,1.77$ & 0.37 \\
\hline Age $\geq 50$ years & 1.0 & 1.21 & $0.98,1.50$ & 1.04 & $0.83,1.30$ & 0.53 \\
\hline Normal weight $\left(\mathrm{BMI}<25 \mathrm{~kg} / \mathrm{m}^{2}\right)$ & 1.0 & 1.59 & $0.98,2.58$ & 1.24 & $0.78,1.99$ & 0.27 \\
\hline Overweight/obese $\left(\mathrm{BMl} \geq 25 \mathrm{~kg} / \mathrm{m}^{2}\right)$ & 1.0 & $1 \cdot 14$ & $0.95,1.37$ & 1.26 & $1.02,1.55$ & 0.034 \\
\hline \multicolumn{7}{|l|}{ Hypertension-DP2 } \\
\hline All subjects & 1.0 & 1.00 & $0.83,1.22$ & 0.91 & $0.75,1.10$ & 0.31 \\
\hline Males & 1.0 & 0.99 & $0.76,1.29$ & 0.92 & $0.71,1 \cdot 21$ & 0.55 \\
\hline Females & 1.0 & 1.00 & $0.76,1.33$ & 0.89 & $0.67,1.18$ & 0.42 \\
\hline Age $<50$ years & 1.0 & 0.99 & $0.72,1.36$ & 0.84 & $0.58,1.22$ & 0.37 \\
\hline Age $\geq 50$ years & 1.0 & 1.09 & $0.85,1.40$ & 1.03 & $0.81,1.30$ & 0.84 \\
\hline Normal weight $\left(\mathrm{BMl}<25 \mathrm{~kg} / \mathrm{m}^{2}\right)$ & 1.0 & 0.83 & $0.58,1.21$ & 0.83 & $0.51,1.36$ & 0.48 \\
\hline Overweight/obese $\left(\mathrm{BMl} \geq 25 \mathrm{~kg} / \mathrm{m}^{2}\right)$ & 1.0 & 1.05 & $0.83,1.33$ & 0.95 & $0.78,1.16$ & 0.60 \\
\hline
\end{tabular}

* Poisson regression with robust error variance was used to test for significant differences between tertiles of dietary pattern. Analyses were adjusted for age, sex, smoking status, physical activity, level of education, urban or rural location, energy misreporting, dieting or atypical dietary intake on day of reporting and female life stage (women only). Hypertension outcomes were additionally adjusted for BMI. Covariates were excluded if they were included in the outcome (i.e. stratification by sex was not adjusted for sex).

† Results are based on $n 4843$ because of exclusion of underweight individuals.

This may be because of methodological differences as that study $^{(34)}$ utilised factor analysis with specific loading cut-offs, or that these relationships are not evident in adolescents. Nevertheless, previous studies in children have identified that a DP characterised by high DED, low fibre density and high fat intake was associated with increased fatness ${ }^{(12)}$. A prospective study in 141 adults identified that a diet high in fat, cholesterol and $\mathrm{Ca}$ was associated with an increase in BMI and waist:hip ratio after a 6-year follow-up ${ }^{(25)}$, whereas a study in 24958 adults showed that a DP characterised by high-fibre and low-fat foods could help maintain body weight during a 4-year followup $^{(14)}$. The latter study by Schulz et $a l^{(14)}$ identified that this healthy diet was only beneficial for weight maintenance in women $<50$ years of age and males $>50$ years of age. Our findings identified that DP1 was only inversely associated with prevalence of overweight or obesity in both men and women and only individuals $<50$ years. This may be a result of individuals with higher DP1 being older and living a healthier lifestyle, although our analyses were adjusted for age and key lifestyle characteristics.

A noteworthy outcome in our DP was that we identified two DP associated with opposing obesity prevalence, which were characterised by high intakes of natural sugars and added sugars, respectively. To the authors' knowledge, no previous 
data-driven DP have investigated two such DP in relation to obesity prevalence in adults. However, our findings support a recent study in children and adolescents, where RRR-derived DP high in percentage energy from fat and free sugars, which were characterised by high factor loadings for sugary drinks and confectionery/chocolate, were associated with greater risk of obesity $^{(35)}$. Intakes of added sugars in Australian adults are in excess of WHO recommendations ${ }^{36)}$ and there is an increasing body of evidence suggesting that this is a risk factor for obesity $^{(37)}$ and chronic disease ${ }^{(38)}$. As a result, our study has highlighted a critical public health message that, although natural and added sugars are chemically comparable, they may have opposing influences on obesity prevalence because of the influence of the surrounding food matrix. More specifically, the role of other nutrients within a food item (such as fibre and fat) supports the need to adopt a food-based approach for understanding obesity risk.

Studies evaluating the relationship between DP and hypertension are limited ${ }^{(4)}$, particularly ones using only data-driven approaches. The Dietary Approaches to Stop Hypertension trial provided strong evidence for the protective effect of low-fat dairy products and fruit and vegetables in the protection against hypertension $^{(39)}$, with subsequent studies further highlighting the role of dairy products in particular ${ }^{(40)}$. Although the factor loading for low-fat dairy products was low in Hypertension-DP1 (-0.14), its direction was consistent with the literature and may have contributed towards the overall effect of Hypertension-DP1 on hypertension. Our study confirms the detrimental role of processed meat in relation to hypertension ${ }^{(41)}$, which has been identified in other DP analyses. For example, a prospective study in 1037 adults (21-year follow-up from childhood) identified that a diet high in milk, butter and processed meats was associated with higher systolic blood pressure among women ${ }^{(11)}$, whereas in a study of 3042 adults (5-year follow-up) a diet high in sweets, red meat, margarine and salty nuts was positively associated with both systolic and diastolic blood pressures ${ }^{(42)}$. To date, only one study has used RRR to assess DP and hypertension in adults ${ }^{(15)}$. This recent cross-sectional study in 1026 Brazilian women used $\mathrm{Na}, \mathrm{K}$ and SFA intakes and identified only one DP that was associated with lower prevalence of hypertension and among women between 40 and 60 years of age only (PR 0.62; $95 \% \mathrm{CI}$ $0.43,0.91 ; P=0.049)^{(15)}$. This DP was characterised by high intakes of vegetables and low intakes of processed meat. Although the study by da Silva et al. was on women only and comparisons were difficult, our findings for Hypertension-DP1 support the importance of levels of vegetables and processed meat intake in determining hypertension prevalence.

\section{Strengths and limitations}

A strength of the present study is that it was conducted in a large ( $n$ 4908), nationally representative sample of Australian adults, and thus our results are generalisable to the wider Australian population. Furthermore, food intakes were derived from two 24-h recalls, which provide a more accurate estimate of dietary intakes than FFQ-based data, but may be less reflective of long-term intakes. Furthermore, in contrast to the majority of previous DP research, we used RRR, which derived
DP that explain the variance in the response variables - in this case, nutrients identified as important for obesity and hypertension. The major strength of using RRR is that it combines both a priori and a posteriori information of the association between the exposure and the outcome by defining nutrient intakes known to be linked to the outcome of interest and explaining variation in these variables according to food group intakes. As a result, in contrast to purely data-driven approaches, such as PCA, RRR can explain variation in nutrient intakes by linear functions of food intakes ${ }^{(5)}$. Taken together, RRR generates DP that may be more appropriate for the diseases of interest $^{(7)}$. Although DP generated from RRR are specific to the dietary intakes of the cohort, and are thus criticised for their generalisability when compared with diet quality scores, RRR has the advantage of being less sensitive to violations of assumptions concerning directional relations because it does not fix expected directions of effects when determining response variables ${ }^{(5)}$. Furthermore, to our knowledge, the present study is the first study to demonstrate robustness of RRR DP by estimating usual dietary intakes and comparing the subsequent RRR DP and their relationships with the main outcomes. Future research in DP should consider inclusion of methodologies to estimate usual dietary intakes.

Nevertheless, RRR has several limitations. First, although the food groups are based on AUSNUT 2011-13, the number and definitions of the food groups are somewhat subjective and may have affected the derived DP. Although RRR gives equal weight to all food groups, regardless of the amount of foods consumed, unlike PCA, it is not affected by standardisation of food groups. Second, although the choice of response variables used in the present analysis is based on published literature, these are selected by researchers, and the use of different response variables may result in a different DP. A potential limitation of the present study was that we generated and fitted RRR DP in the same data set. To rule out any effect of over-fitting and to show generalisability of RRR DP, future studies should consider deriving and applying DP in independent data sets, as has been done in some studies previously ${ }^{(43)}$. Future studies should also consider using the patterns derived in the present study to verify our findings. A further limitation of this study was that because of its cross-sectional design we were unable to infer any causal relationships between DP and prevalence of obesity and hypertension. Reverse causations, where individuals may have changed their diet to reduce their risk of obesity or hypertension, could not be investigated in the present analysis. In addition, although our analyses were adjusted for multiple confounders, we cannot discount the possibility of residual confounding. Nonetheless, comparison of crude and adjusted models for the associations between DP and obesity and hypertension showed that inclusion of covariates in our models (most notably age and sex) considerably strengthened the associations observed (data not shown). Although we adjusted for energy misreporting, 24-h recalls are subject to misreporting bias, and therefore a further repeat of the recall would have improved the accuracy of our dietary intake estimations ${ }^{(44)}$. Nevertheless, validation of the United States Automated Multiple-Pass Method 24-h dietary recall, on which the present recall is based, has shown good reporting accuracy for our chosen response variables ${ }^{(45-47)}$. Information on hypertensive medication was not available in the 
NNPAS, which may have contributed towards residual confounding when assessing hypertension-related outcomes. Longitudinal studies in a nationally representative sample are warranted to determine whether these DP will predict lower risk of hypertension or obesity.

\section{Implications of findings}

The present results have implications for the design of future dietary recommendations for obesity and hypertension prevention. Our findings provide evidence to support the current WHO dietary recommendations to reduce intakes of energy-dense foods and foods containing high amounts of $\mathrm{Na}$, SFA and added sugars and increase intakes of foods rich in K, PUFA, natural sugars and dietary fibre for the prevention of obesity and hypertension. Public health interventions are urgently needed to address these challenges.

\section{Conclusions}

A DP characterised by low DED, high fibre density and high sugars intake (primarily from fruits) was associated with lower prevalence of being overweight or obese, whereas a DP with low fibre density and high sugars intake (primarily from chocolate and fruit drinks) was associated with increased prevalence of being overweight or obese. Furthermore, a DP characterised by low fibre density and high Na:K and high SFA: PUFA ratios was associated with increased prevalence of hypertension. Prospective studies are warranted to further investigate these findings.

\section{Acknowledgements}

K. M. L. acknowledges the support from the Australian Department of Education Endeavour Fellowship and the Alfred Deakin Postdoctoral Research Fellowship. S. A. M. is supported by an NHMRC Career Development Fellowship Level 2, ID1104636, and was previously supported by an ARC Future Fellowship (2011-2015, FT100100581).

The authors' responsibilities were as follows: K. M. L. and S. A. M. contributed to the study design. K. M. L. performed the statistical analysis for the manuscript and drafted the paper. All authors contributed to a critical review of the manuscript during the writing process. All authors approved the final version to be published.

None of the authors had any personal conflicts of interest.

\section{Supplementary material}

To view supplementary material for this article, please visit https://doi.org/10.1017/S0007114516004505

\section{References}

1. World Health Organization (2013) A Global Brief on Hypertension. Silent Killer, Global Public Health Crisis. Geneva: WHO. http://www.who.int/cardiovascular_diseases/ publications/global_brief_hypertension/en/ (accessed February 2016).
2. World Health Organization (2003) Diet, Nutrition and the Prevention of Chronic Diseases. Technical Report Series no. 916. Geneva: WHO. http://www.who.int/dietphysicalactivity/ publications/trs916/en/ (accessed January 2016).

3. World Health Organization (2003) Food Based Dietary Guidelines in the WHO European Region. Geneva: WHO. http://www.euro. who.int/_data/assets/pdf_file/0017/150083/E79832.pdf (accessed December 2015).

4. United States Department of Agriculture (2014) A Series of Systematic Reviews on the Relationship Between Dietary Patterns and Health Outcomes. Alexandria, VA: USDA. http://www.nel.gov/vault/2440/web/files/DietaryPatterns/DPR ptFullFinal.pdf (accessed December 2015).

5. Hoffmann K, Schulze MB, Schienkiewitz A, et al. (2004) Application of a new statistical method to derive dietary patterns in nutritional epidemiology. Am J Epidemiol 159, 935-944.

6. Hoffmann K, Zyriax B-C, Boeing H, et al. (2004) A dietary pattern derived to explain biomarker variation is strongly associated with the risk of coronary artery disease. Am J Clin Nutr 80, 633-640.

7. Biesbroek S, van der A DL, Brosens MC, et al. (2015) Identifying cardiovascular risk factor-related dietary patterns with reduced rank regression and random forest in the EPICNL cohort. Am J Clin Nutr 102, 146-154.

8. Kroke A (2004) RE: 'Application of a new statistical method to derive dietary patterns in nutritional epidemiology'. Am J Epidemiol 160, 1132.

9. Togo P, Osler M, Sørensen TI, et al. (2001) Food intake patterns and body mass index in observational studies. Int $\mathrm{J}$ Obes Relat Metab Disord 25, 1741-1751.

10. McNaughton SA, Mishra GD \& Brunner EJ (2009) Food patterns associated with blood lipids are predictive of coronary heart disease: the Whitehall II study. Br J Nutr 102, 619-624.

11. Mikkilä V, Räsänen L, Raitakari OT, et al. (2007) Major dietary patterns and cardiovascular risk factors from childhood to adulthood. The Cardiovascular Risk in Young Finns Study. Br J Nutr 98, 218-225.

12. Johnson L, Mander AP, Jones LR, et al. (2008) Energy-dense, low-fiber, high-fat dietary pattern is associated with increased fatness in childhood. Am J Clin Nutr 87, 846-854.

13. Sherafat-Kazemzadeh R, Egtesadi S, Mirmiran P, et al. (2010) Dietary patterns by reduced rank regression predicting changes in obesity indices in a cohort study: Tehran Lipid and Glucose Study. Asia Pac J Clin Nutr 19, 22-32.

14. Schulz M, Nöthlings U, Hoffmann K, et al. (2005) Identification of a food pattern characterized by high-fiber and low-fat food choices associated with low prospective weight change in the EPIC-Potsdam cohort. J Nutr 135, 1183-1189.

15. da Silva BDP, Neutzling MB, Camey S, et al. (2014) Dietary patterns and hypertension: a population-based study with women from Southern Brazil. Cad Saúde Pública 30 , 961-971.

16. Australian Bureau of Statistics (2015) Australian Health Survey: users' guide, 2011-13, catalogue no. 4363.0.55.001. Canberra, Australia. http://www.abs.gov.au/ausstats/abs@.nsf/Lookup/ 4363.0.55.001Chapter1002011-13 (accessed December 2015).

17. World Health Organization (2015) BMI classification. Canberra, Australia. http://apps.who.int/bmi/index.jsp?introPage=intro_3.html (accessed December 2015).

18. Australian Bureau of Statistics (2013) 4338.0 - Profiles of Health, Australia, 2011-13. Blood pressure. http://www.abs.gov.au/ ausstats/abs@.nsf/Lookup/by\%20Subject/4338.0 2011-13 Main \%20Features Blood\%20pressure 10011 (accessed December 2015). 
19. Australian Bureau of Statistics (2006) Statistical Geography Volume 1 - Australian Standard Geographical Classification (ASGC). http://www.abs.gov.au/AUSSTATS/abs@.nsf/Lookup/ 1216.0Main+Features1Jul\%202 006?OpenDocument (accessed December 2015).

20. Bliss R (2004) Researchers produce innovation in dietary recall. Agric Res 52, 10-12.

21. Food Standards Australia New Zealand (2015) AUSNUT 2011-13: Australian Food, Supplement and Nutrient Database. http://www. foodstandards.gov.au/science/monitoringnutrients/ausnut/Pages/ about.aspx (accessed December 2015).

22. Huang TT, Roberts SB, Howarth NC, et al. (2005) Effect of screening out implausible energy intake reports on relationships between diet and BMI. Obes Res 13, 1205-1217.

23. Mccrory MA, Hajduk CL \& Roberts SB (2002) Procedures for screening out inaccurate reports of dietary energy intake. Public Health Nutr 5, 873-882.

24. Ma Y, Olendzki BC, Pagoto SL, et al. (2009) Number of 24-hour diet recalls needed to estimate energy intake. Ann Epidemiol 19, 553-559.

25. Sherafat-Kazemzadeh R, Egtesadi S, Mirmiran P, et al. (2010) Dietary patterns by reduced rank regression predicting changes in obesity indices in a cohort study: Tehran Lipid and Glucose Study. Asia Pac J Clin Nutr 19, 22-32.

26. Cook NR, Appel LJ \& Whelton PK (2014) Lower levels of sodium intake and reduced cardiovascular risk. Circulation 129, 981-989.

27. Ledikwe JH, Blanck HM, Khan LK, et al. (2005) Dietary energy density determined by eight calculation methods in a nationally representative United States population. J Nutr 135, 273-278.

28. Wrieden WL, Armstrong J, Anderson AS, et al. (2015) Choosing the best method to estimate the energy density of a population using food purchase data. J Human Nutr Diet 28, 126-134.

29. Food Standards Australia New Zealand (2016) Classification of foods and dietary supplements. http://www.foodstandards. gov.au/science/monitoringnutrients/ausnut/classificationofsupps/ Pages/default.aspx (accessed July 2016).

30. Schulze MB, Hoffmann K, Kroke A, et al. (2003) An approach to construct simplified measures of dietary patterns from exploratory factor analysis. Br J Nutr 89, 409-418.

31. Harttig U, Haubrock J, Knuppel S, et al. (2011) The MSM program: web-based statistics package for estimating usual dietary intake using the Multiple Source Method. Eur J Clin Nutr 65, S87-S91.

32. Haubrock J, Nöthlings U, Volatier J-L, et al. (2011) Estimating usual food intake distributions by using the multiple source method in the EPIC-Potsdam Calibration Study. J Nutr 141, 914-920.

33. de Oliveira Santos R, Fisberg RM, Marchioni DM, et al. (2015) Dietary patterns for meals of Brazilian adults. Br J Nutr 114, 822-828.
34. McNaughton SA, Ball K, Mishra GD, et al. (2008) Dietary patterns of adolescents and risk of obesity and hypertension. J Nutr 138, 364-370.

35. Ambrosini GL, Johns DJ, Northstone K, et al. (2016) Free sugars and total fat are important characteristics of a dietary pattern associated with adiposity across childhood and adolescence. J Nutr 146, 778-784.

36. Lei L, Rangan A, Flood VM, et al. (2016) Dietary intake and food sources of added sugar in the Australian population. Br J Nutr 115, 868-877.

37. Te Morenga L, Mallard S \& Mann J (2013) Dietary sugars and body weight: systematic review and meta-analyses of randomised controlled trials and cohort studies. BMJ $\mathbf{3 4 6}$, e7492.

38. Te Morenga LA, Howatson AJ, Jones RM, et al. (2014) Dietary sugars and cardiometabolic risk: systematic review and meta-analyses of randomized controlled trials of the effects on blood pressure and lipids. Am J Clin Nutr 100, 65-79.

39. Appel LJ, Moore TJ, Obarzanek E, et al. (1997) A clinical trial of the effects of dietary patterns on blood pressure. $N$ Engl J Med 336, 1117-1124.

40. Livingstone KM, Lovegrove JA, Cockcroft JR, et al. (2013) Does dairy food intake predict arterial stiffness and blood pressure in men?: Evidence from the Caerphilly Prospective Study. Hypertension 61, 42-47.

41. Lajous M, Bijon A, Fagherazzi G, et al. (2014) Processed and unprocessed red meat consumption and hypertension in women. Am J Clin Nutr 100, 948-952.

42. Panagiotakos D, Pitsavos C, Chrysohoou C, et al. (2009) Dietary patterns and 5-year incidence of cardiovascular disease: a multivariate analysis of the ATTICA study. Nutr Metab Cardiovasc Dis 19, 253-263.

43. Nöthlings U, Murphy SP, Wilkens LR, et al. (2008) A food pattern that is predictive of flavonol intake and risk of pancreatic cancer. Am J Clin Nutr 88, 1653-1662.

44. Shamah-Levy T, Rodríguez-Ramírez S, Gaona-Pineda EB, et al. (2016) Three 24-hour recalls in comparison with one improve the estimates of energy and nutrient intakes in an urban Mexican population. J Nutr 146, 1043-1050.

45. Rhodes DG, Murayi T, Clemens JC, et al. (2013) The USDA Automated Multiple-Pass Method accurately assesses population sodium intakes. Am J Clin Nutr 97, 958-964.

46. Moshfegh AJ, Rhodes DG, Baer DJ, et al. (2008) The US Department of Agriculture Automated Multiple-Pass Method reduces bias in the collection of energy intakes. Am J Clin Nutr 88, 324-332.

47. Blanton CA, Moshfegh AJ, Baer DJ, et al. (2006) The USDA Automated Multiple-Pass Method accurately estimates group total energy and nutrient intake. $J$ Nutr 136, 2594-2599. 